\title{
NKAP plays an oncogenic function partly through AKT signaling pathway in hepatocellular carcinoma
}

\author{
T. SONG ${ }^{1}$, J. Y. LIU $2, *$ J. J. YANG ${ }^{2, *}$ \\ ${ }^{1}$ Department of Medical Imaging, Changhai Hospital of Second Military Medical University of Chinese PLA, Shanghai, China; ${ }^{2}$ Department of \\ Interventional Radiology, Changhai Hospital of Second Military Medical University of Chinese PLA, Shanghai, China \\ *Correspondence: ljy6259@126.com; jijinyang@sina.com
}

Received December 12, 2018 / Accepted June 5, 2019

\begin{abstract}
NF- $\kappa \mathrm{B}$ activating protein (NKAP) is a highly conserved protein involved in transcriptional repression, immune cell development, maturation, T cell acquisition of functional competency and maintenance of hematopoiesis. Here, we first explore the function of NKAP in hepatocellular carcinoma (HCC). We found that NKAP was highly expressed in HCC tissues and associated with a poor patient survival. CCK8 assay showed that NKAP knockdown significantly decreased cell viability of HuH7 and Hep3B HCC cell lines. Cell invasion, tested by transwell assays, was significantly inhibited by NKAP knockdown in HuH7 and Hep3B cells $(\mathrm{p}<0.05)$. Percentage of cell apoptosis was significantly increased by NKAP knockdown in HuH7 cells (6.5\% to $12.5 \%$ ) and in Hep3B cells (8.3\% to 27.3\%). Furthermore, western blot results indicated that NKAP silencing upregulated the expression of pro-apoptotic proteins Bax and Caspase3-P17 while downregulated anti-apoptotic protein Bcl2. Finally, AKT signaling pathway was evaluated to reveal the underlying mechanism of NKAP in HCC cells. It was suggested that NKAP knockdown decreased the phosphorylation level of AKT and the expression of its downstream members p70S6K and Cyclin D1. Furthermore, we demonstrated that NKAP knockdown also played an oncogenic role in human gastric cancer AGS and MKN45 cells. In conclusion, our study for the first time reveals that NKAP promotes the proliferation and invasion in HCC cell lines at least partly through AKT signaling pathway.
\end{abstract}

Key words: NKAP, HCC, apoptosis, AKT

Hepatocellular carcinoma (HCC) is one of the most lifethreatening tumors worldwide, leading to one third of cancer cases and 695, 900 cancer deaths worldwide every year with China accounting for nearly 50\% [1, 2]. Previous studies have revealed many factors contributing to HCC pathogenesis, such as hepatitis $\mathrm{B} / \mathrm{C}$ virus infection, alcohol abuse, liver cirrhosis, gene mutation, and so on [3]. Despite great advances in HCC treatment strategies such as sorafenib, liver transplantation and percutaneous ablation, the survival rate of HCC patients remains very poor, 3-5\% within 5 years [3-7]. With the development of bioinformatics, gene expression profile of HCC has been fully characterized and many of the genetic abnormalities contributing to HCC, such as potential oncogenes and tumor suppressor genes, are well known [8-10]. These efforts have greatly facilitated the early diagnosis and accurate treatment of HCC.

NF- $\kappa \mathrm{B}$ activating protein (NKAP) was initially identified as a positive regulator of $\mathrm{NF}-\kappa \mathrm{B}$ activation [11]. Recent studies of NKAP mostly focus on immune cells, including $\mathrm{T}$ cells, Invariant Natural Killer T (iNKT) cells and regulatory T
(Treg) cells [12-16]. It is reported that NKAP plays an important role in $\mathrm{T}$ cells and iNKT development by repression of Notch pathway $[13,14]$. T cells maturation and acquisition of functional competency also requires NKAP but not through Notch pathway [15]. NKAP regulates iNKT cell proliferation and differentiation into ROR- $\gamma$ t expressing NKT17 cells [12]. Tregs also undergo a maturation process, which requires NKAP to acquire complement resistance after thymic egress [16]. Other study also shows that NKAP is required for the maintenance and survival of adult hematopoietic stem cells and a potentially important regulator of adult neurogenesis by Notch and/or Notch and/or NF- $\kappa B$ pathways [17, 18]. In addition, NKAP is also reported to participate in some fundamental biological processes. For instance, NKAP acts as a nuclear speckle protein involved in RNA splicing and processing [19] and anchors CENP-E to kinetochores to ensue chromosome alignment in mitosis and its dysregulation can lead to chromosomal instability, which might result in tumorigenesis [20]. However, there is no direct evidence explaining the roles of NKAP in tumor progression. 
In this study, we show that NKAP was upregulated in HCC tissues compared with paracarcinoma tissues, and high expression of NKAP predicts a poor prognosis in patients with HCC. The function analysis revealed that NKAP restrained the proliferative and invasive abilities of human $\mathrm{HuH7}$ and Hep3B cells. The underlying action mechanism of NKAP was also explored, which indicated that NKAP knockdown led to the activation of apoptosis pathway and inactivation of AKT pathway. In conclusion, our study extends the understanding of the role of NKAP as a tumor promoter.

\section{Materials and methods}

Cell culture and transfection. HCC cell lines, $\mathrm{HuH} 7$ and Hep3B and human gastric cancer cell lines AGS and MKN45 were purchased from ATCC. The cells were cultured in RPMI-1640 medium containing 10\% fetal bovine serum (FBS) at $37^{\circ} \mathrm{C}$ in $5 \% \mathrm{CO}_{2}$. After the cells reached $80 \%$ confluence, NKAP was knocked down in HuH7 and Hep3B cells using Lipofectamine 2000 (Invitrogen, Carlsbad, CA, USA) according to the manufacturer's instructions. Briefly, Lipofectamine $2000(10 \mu \mathrm{l})$ was added to $250 \mu \mathrm{l}$ DMEM medium without serum and incubated for $5 \mathrm{~min}$ at room temperature. NKAP siRNA (siNKAP, $5 \mathrm{ml}$ ) or a scrambled siRNA (siNC, $5 \mathrm{ml}$ ) was added to $250 \mathrm{ml}$ RPMI-1640 medium without serum. After the 5 min incubation, the diluted siRNA was mixed with the diluted Lipofectamine 2000 and incubated for $30 \mathrm{~min}$ at room temperature. The final concentration of siRNA was $50 \mathrm{nM}$. Cell medium was replaced with the above siRNA-contained medium. Cells were then cultured at $37^{\circ} \mathrm{C}$ in a $\mathrm{CO}_{2}$ incubator for $24 \mathrm{~h}$.

Analysis of mRNA expression. Total RNA was isolated from cells using a high pure RNA isolation kit (Bioteke Corporation, Beijing, China).One mg of RNA was then reverse transcribed to cDNA using a Transcriptor first strand cDNA synthesis kit (Roche, Shanghai, China). Real-time PCR amplification was used via ABI Prism 7300 sequence detector (Applied Biosystems) and SYBR Green reagent. The PCR reaction was performed as follows: an initial stage of $95^{\circ} \mathrm{C}$ for $30 \mathrm{sec}$, then a two-step program of $95^{\circ} \mathrm{C}$ for $5 \mathrm{sec}$, $60^{\circ} \mathrm{C}$ for $31 \mathrm{sec}$ over 40 cycles and were performed in triplicate. $\beta$-actin was used as an internal control.

Immunohistochemical assay. Immunohistochemical analysis was performed by using PV9000 two-step immunohistochemical method (ZSGB-BIO Cor., Beijing; catalog number: PV-9000) according to manufacturers' instructions. The tissues were obtained from Changhai Hospital of Second Military Medical University of Chinese PLA. This work has been approved by the ethics committees at Changhai Hospital of Second Military Medical University of Chinese PLA. All patients provided written informed consent. The sections of HCC tumor or paracancerous tissues were prepared with $8 \mu \mathrm{m}$ thickness. Sodium citrate buffer $(\mathrm{pH} 6.0)$ and $3 \% \mathrm{H}_{2} \mathrm{O}_{2}$ were used for antigen retrieval and endogenous peroxidase clearance, respectively. Then the sections were blocked with goat serum for $1 \mathrm{~h}$ at room temperature and incubated with primary antibody, anti-NKAP (Cat\#ab229096, Abcam). DAB developer was used for slides development. After doubled staining with hematoxylin, dehydrated with gradient ethanol and mounted with neutral resins, tissue sections were observed under microscope and Image Pro Plus6.0 (Media Cybernetics) was used to analyze images. 3-5 random fields from each slice $(\times 400)$ were selected to evaluate NKAP expression. NKAP expression was assessed as 1) positive $(+)$ when the percentage of immuno-reactive cells was more than $10 \%$, and 2) negative (-) when immuno-reactive cells accounted for less than $10 \%$. Two investigator blind to each other recorded and calculated cell number.

CCK8 assay. Cell Counting Kit-8 (CCK-8) was used to test cell proliferation. Cells were transfected with siNKAP or siNC following plating into 96-well plate at a density of 5000 per well. Ten $\mu$ l CCK8 reagent was added to each well and incubated for $2 \mathrm{~h}$ every $24 \mathrm{~h}$. OD values at $450 \mathrm{~nm}$ were measured to plot proliferation curve.

Transwell invasion assay. To determine the invasive ability of cancer cells, the upper chamber of a transwell was pre-coated with Matrigel. Five hundred $\mu \mathrm{l}$ serum-free medium containing cells and $500 \mu \mathrm{l}$ complete (10\% FBS) were respectively added to the upper and lower compartment of the transwell. After $24 \mathrm{~h}$, the non-invaded cells were removed and invaded cells were stained with crystal violet. Then invaded cells were visualized using an inserted microscope and counted.

Cell apoptosis assay. HuH7 and Hep3B cells were transfected with siNKAP for $48 \mathrm{~h}$ and collected by trypsinization. After washed with PBS twice, cells were washed with PBS buffer twice, centrifuged and resuspended in $1 \mathrm{X}$ binding buffer containing dyes of Annexin V-FITC and propidium iodide (PI). After incubation for $15 \mathrm{~min}$ in dark, cell distribution was analyzed by using flow cytometry.

Western blot. $\mathrm{HuH} 7$ and Hep3B cells transfected with siNKAP or siNC were collected, lysed and centrifuged at $4{ }^{\circ} \mathrm{C}$. Total proteins were separated by SDS-PAGE. Then the protein bands were transferred to PVDF membranes, blocked in non-fat milk for $2 \mathrm{~h}$, incubated with primary antibodies overnight at $4^{\circ} \mathrm{C}$ and secondary antibodies for $1 \mathrm{~h}$. After washing with TBST for 3 times, protein bands were detected using an ECL development system. The primary antibodies included anti-NKAP (Cat\#ab229096, Abcam), anti-Bcl-2 (Cat ${ }^{*}$ ab32124, Abcam), anti-Bax (Cat $\left.{ }^{*} a b 32503, A b c a m\right)$, anti-Caspase3-P17-specific (Cat\#25546-1-AP, Proteintech), anti-p-Akt (Cat\#ab81283, Abcam), anti-Akt (Cat\#ab32505, Abcam), anti-p70S6K (Cattab32529, Abcam), anti-CyclinD1 (Cat ${ }^{*} a b 40754$, Abcam) and anti-GAPDH (Cat ${ }^{*}$ ab8245, Abcam). The secondary antibodies were obtained from Proteintech. The Image J software was utilized to quantify the density of each band.

Statistical analysis. All data were the representative of at least 3 independent experiments. Differences were evaluated by the Student's t-test. A p-value $<0.05$ was considered as statistically significant. 


\section{Results}

NKAP is upregulated in HCC and represents a poor prognosis. Along with advances in RNA sequencing technology, a large number of tumor-related RNA expression information is mined by such projects as TCGA and GTEx, providing us with great insight into gene function and convenience of finding diagnostic biomarkers or therapeutic targets for diseases [21-23]. GEPIA (http://gepia.cancer-pku. $\mathrm{cn}$ ) is an interactive RNA expression analysis website that integrates RNA expression information from TCGA and GTEx projects and provides customers with a convenient and fast search pattern [24]. Here, we searched on GEPIA the expression of NKAP in 369 HCC samples and 160 normal controls. The result is shown in Figure S1A, which indicates a significant upregulation of NKAP in HCC. GEPIA also provides patient survival analysis, based on gene expression levels, to assess the prognosis value of a given gene. For NKAP in HCC, we found that the survival rate of patients with high NKAP expression is significantly lower than those with a low NKAP expression $(\mathrm{p}=0.024)$, both groups containing 182 samples (Figure S1B). In addition, we investigated the expression of NKAP in HCC tumor tissues by IHC of paired
Table 1. NKAP expression and the relationship between clinical pathological features of HCC patients.

\begin{tabular}{|c|c|c|c|c|}
\hline \multirow{2}{*}{$\begin{array}{l}\text { Clinic pathologic } \\
\text { feature }\end{array}$} & \multirow{2}{*}{$\begin{array}{l}\text { Cases } \\
(\mathbf{n})\end{array}$} & \multicolumn{2}{|c|}{ NKAP level } & \multirow[b]{2}{*}{ p-value } \\
\hline & & $\begin{array}{c}\text { High } \\
\text { expression }(\mathbf{n})\end{array}$ & $\begin{array}{c}\text { Low } \\
\text { expression (n) }\end{array}$ & \\
\hline \multicolumn{5}{|l|}{ Age } \\
\hline$\leq 50$ & 38 & 23 & 15 & \multirow{2}{*}{0.521} \\
\hline$>50$ & 40 & 27 & 13 & \\
\hline \multicolumn{5}{|l|}{ Sex } \\
\hline Male & 60 & 45 & 15 & \multirow{2}{*}{$<0.001^{\star}$} \\
\hline Female & 18 & 5 & 13 & \\
\hline \multicolumn{5}{|l|}{ Tumor size } \\
\hline$<5 \mathrm{~cm}$ & 45 & 35 & 10 & \multirow{2}{*}{$0.006^{*}$} \\
\hline$\geq 5 \mathrm{~cm}$ & 33 & 15 & 18 & \\
\hline \multicolumn{5}{|l|}{ HBV infection } \\
\hline Absent & 20 & 15 & 5 & \multirow{2}{*}{0.176} \\
\hline Present & 58 & 35 & 23 & \\
\hline \multicolumn{5}{|l|}{ Metastasis } \\
\hline Absent & 52 & 40 & 12 & \multirow{2}{*}{$<0.001^{\star}$} \\
\hline Present & 26 & 10 & 16 & \\
\hline \multicolumn{5}{|l|}{ Pathological grade ${ }^{*}$} \\
\hline I-II & 44 & 22 & 22 & \multirow{2}{*}{$0.003^{*}$} \\
\hline III-IV & 34 & 28 & 6 & \\
\hline
\end{tabular}
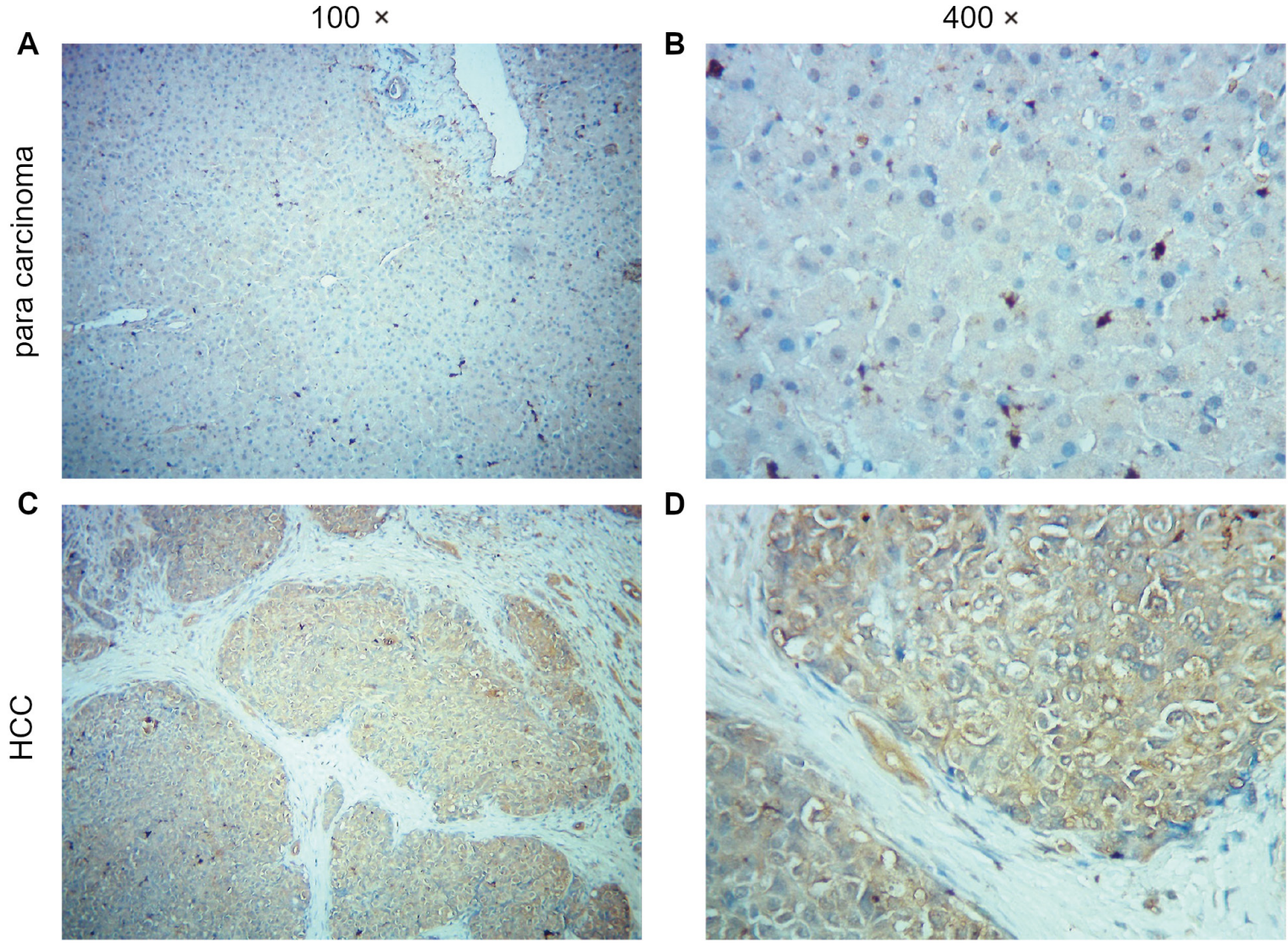

Figure 1. Endogenous levels of NKAP in HCC and paracarcinoma tissues is tested by immunohistochemical assay. A) NKAP expression in paracarcinoma tissue in patients with $\mathrm{HCC}(\times 100)$; B) NKAP expression in paracarcinoma tissue in patients with $\mathrm{HCC}(\times 400)$; $\mathrm{C}) \mathrm{NKAP}$ expression in cancer tissue in patients with HCC $(\times 100)$; D) NKAP expression in cancer tissue in patients with $\mathrm{HCC}(\times 400)$. HCC, hepatocellular carcinoma. 
carcinoma and paracarcinoma tissues using an anti-NKAP antibody. It is suggested that compared to paracarcinoma tissues, the expression of NKAP is prominently accelerated in HCC tumor tissues (Figure 1).

The correlation between NKAP expression and clinical pathological features of HCC patients was also investigated (Table 1). Overall, high-expression rate of NKAP in HCC tumor patients is $64.10 \%$ (50/78). NKAP expression has no connection with age but male patients tend to highly express NKAP $(p<0.001)$. In addition, NKAP expression is significantly associated with tumor size, pathological grade and

A

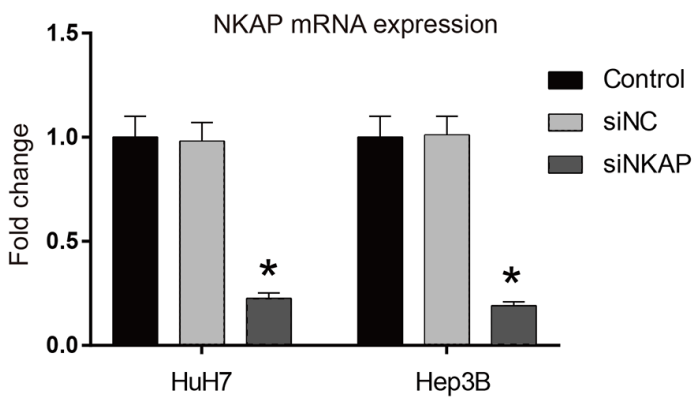

C

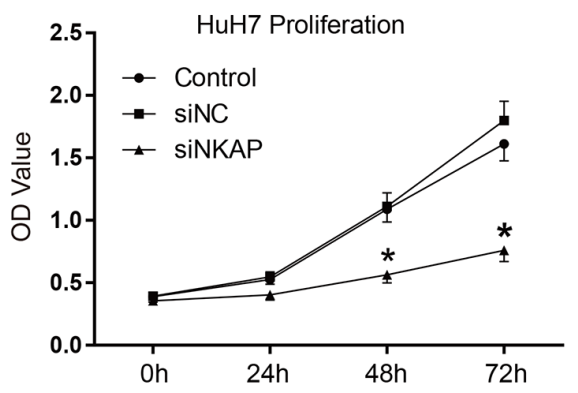

E

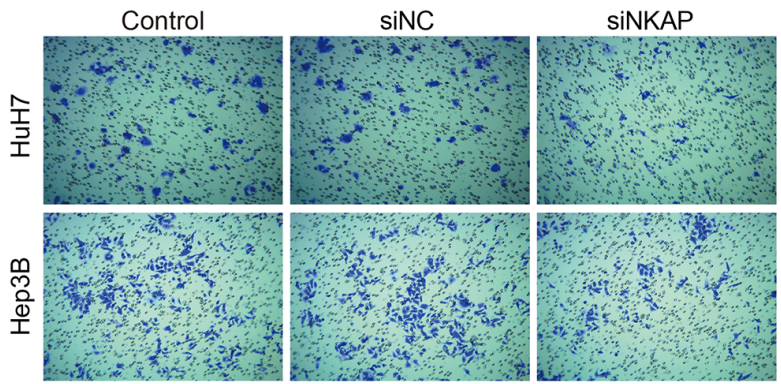

metastasis but has no connection with HBV infection. So it suggests that NKAP is significantly upregulated in HCC and represents a poor prognosis.

NKAP knockdown inhibits HCC cell proliferation and invasion. By using RNA interference technology, we knocked down NKAP in HCC cell lines, HuH7 and Hep3B. The interference efficiency was assessed in RNA level by qRT-PCR assay and protein level by western blot assay. As shown in Figures 2A and 2B, both RNA and protein expression of NKAP were significantly decreased in $\mathrm{HuH7}$ and Hep3B cells.
B
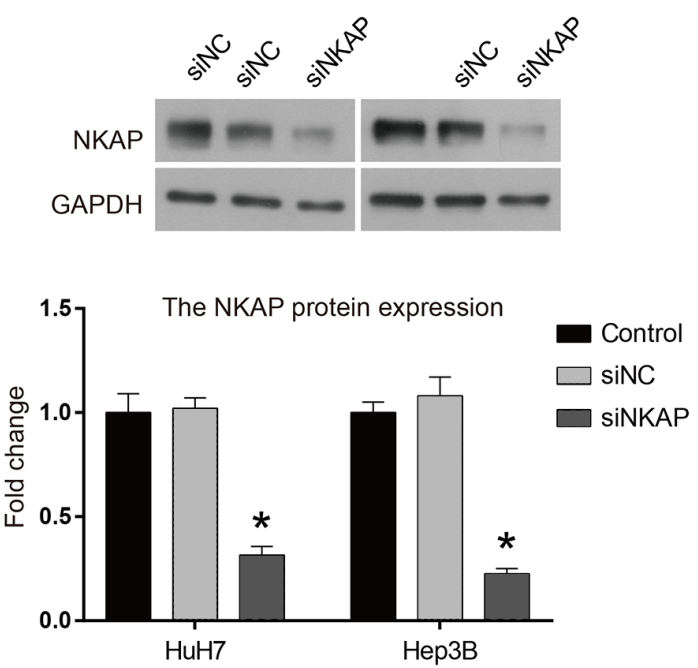

D

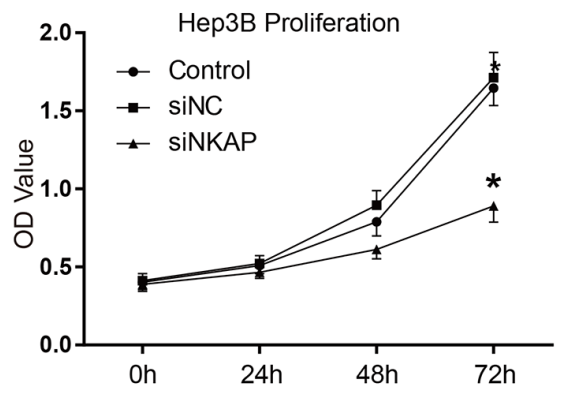

$\mathbf{F}$

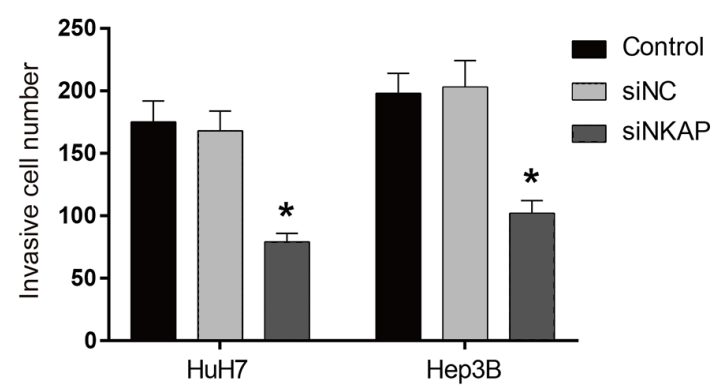

Figure 2. NKAP knockdown significantly inhibits HCC cell proliferation and invasion. A) qPCR demonstrating siNKAP inhibits mRNA expression of NKAP in both $\mathrm{HuH} 7$ and Hep3B cells; B) Western blot verifies the inhibition of NKAP expression in protein level. HCC, hepatocellular carcinoma; C and D) Cell proliferation of $\mathrm{HuH} 7$ and $\mathrm{Hep} 3 \mathrm{~B}$ is detected by CCK8 assay; $\mathrm{E}$ and $\mathrm{F}$ ) Cell invasion $\mathrm{HuH} 7$ and Hep3B is detected by transwell assay. $\mathrm{HCC}$, hepatocellular carcinoma. ${ }^{*}$ represents $\mathbf{p}<0.05$. 
Next, we evaluated the impact of NKAP knockdown on cell proliferation of two cell lines. As shown in Figures 2C and $2 \mathrm{D}$, cell viability of siNKAP group is decreased to about $50 \%$ at $72 \mathrm{~h}$ in both $\mathrm{HuH7}$ and Hep3B cells. Cell invasion was assessed by using transwell assay. As shown in Figure $2 \mathrm{E}$, compared to dense cell distribution in siNC group, cell density in siNKAP group is significantly lower in both $\mathrm{HuH} 7$ and Hep3B cells. Quantification result of cell invasion is shown in Figure 3F, which indicates that invasive cell number of siNKAP group is decreased to $9.54 \%$ and $15.01 \%$ in $\mathrm{HuH} 7$ and Hep3B cells, respectively. In order to determine whether the oncogenic function of NKAP was specific to HCC cells, we also performed proliferation and invasion assays in NKAP silenced gastric cancer cells. As shown in Figure 3, the results indicated that NKAP knockdown also significantly inhibited the proliferation and invasion in human AGS and MKN45 gastric cancer cells.

NKAP knockdown induced HCC cell apoptosis by regulating apoptosis related protein expression. In order to determine whether cell apoptosis contributed to the inhibitory effect of NKAP knockdown on HCC cell proliferation, a flow cytometry apoptosis analysis was performed. The
A

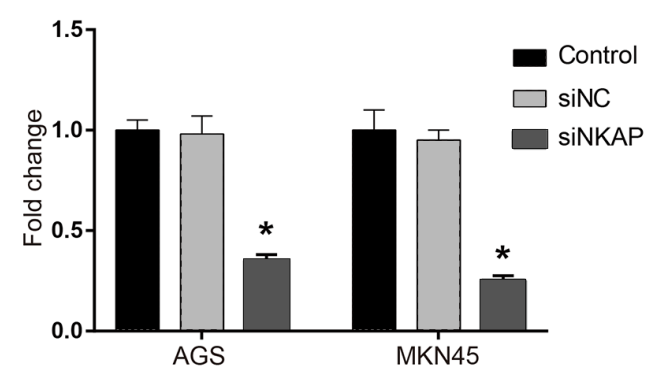

C

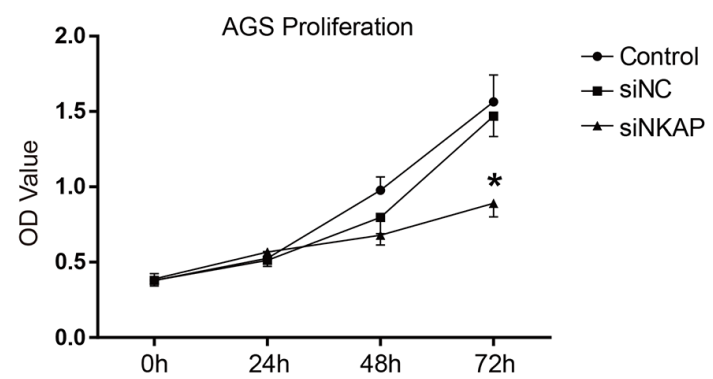

E
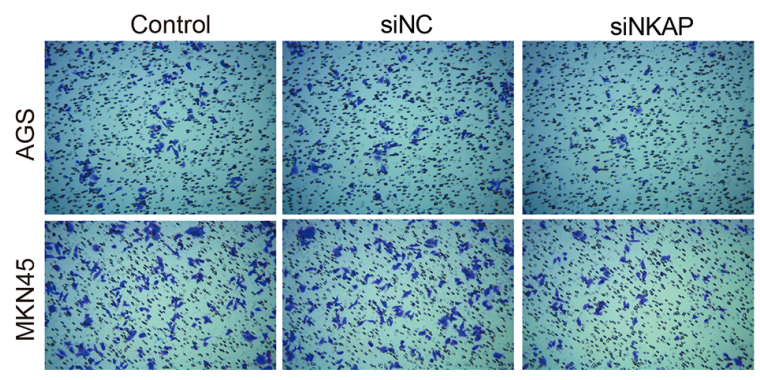

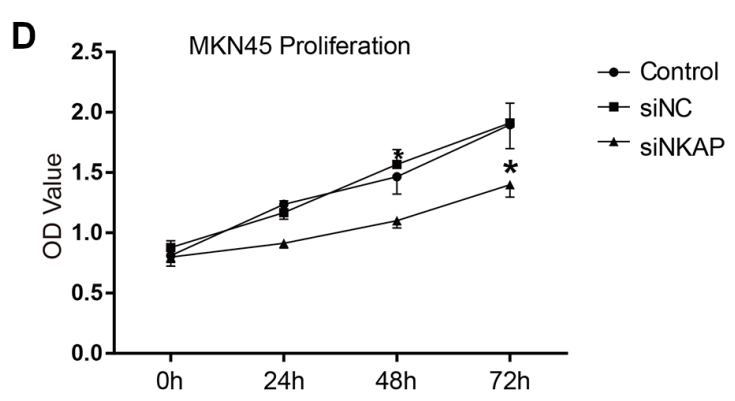

$\mathbf{F}$

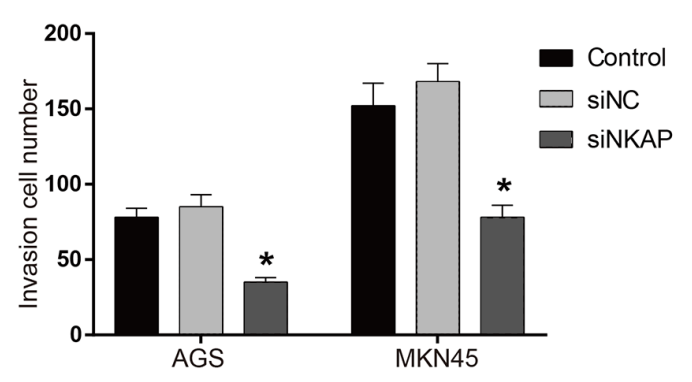

Figure 3. NKAP knockdown significantly inhibits the proliferation and invasion of gastric cancer cells. NKAP was knocked down by using siRNA transfection and NKAP expression was detected on mRNA (A) and protein (B) level. C and D) Cell proliferation of AGS and MKN45 is detected by CCK8 assay; E and F) Cell invasion AGS and MKN45 is detected by transwell assay. ${ }^{*}$ represents $\mathbf{p}<0.05$. 
results in Figures $4 \mathrm{~A}$ and $4 \mathrm{~B}$ show that compared to siNC group, cell apoptosis percentage is significantly increased in siNKAP group in $\mathrm{HuH7}$ cells (6.5\% to $12.5 \%)$ and in Hep3B cells $(8.3 \%$ to $27.3 \%)$. We further investigated the expression of apoptosis related protein by western blot. As shown in Figures 4C-E, in both $\mathrm{HuH7}$ and Hep3B cells, anti-apoptotic protein $\mathrm{Bcl} 2$ is significantly downregulated in NKAP knockdown group while pro-apoptotic protein Bax and CaspaseP17 are significantly upregulated.

NKAP knockdown inhibits the activation of AKT signaling pathway. To elucidate the regulating mechanism of NKAP in HCC, we investigated the effect of NKAP knockdown on AKT signaling pathway in HuH7 and Hep3B cells. When the signaling pathway is activated, AKT is phosphorylated. p-AKT further upregulated the downstream effector proteins, like p70S6K and CyclinD1, which promote protein synthesis or cell cycle progression [25]. As shown in Figure 5, it is suggested that $\mathrm{p}$-AKT and the downstream effectors CyclinD1 and p70S6K are all downregulated by knockdown of NKAP in both cell lines, while AKT expression does not change. The results demonstrate that NKAP knockdown inhibits HCC by suppressing AKT signaling pathway.
A

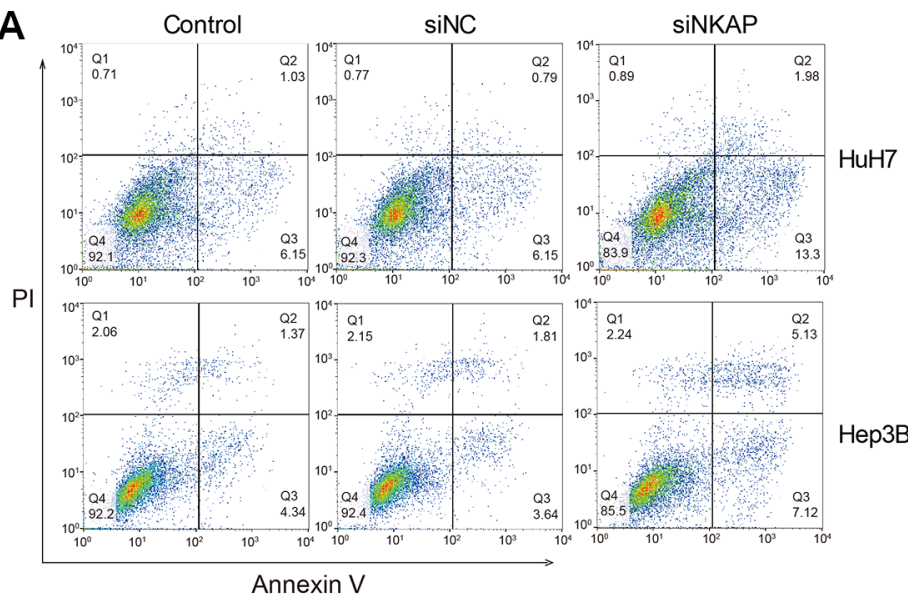

C

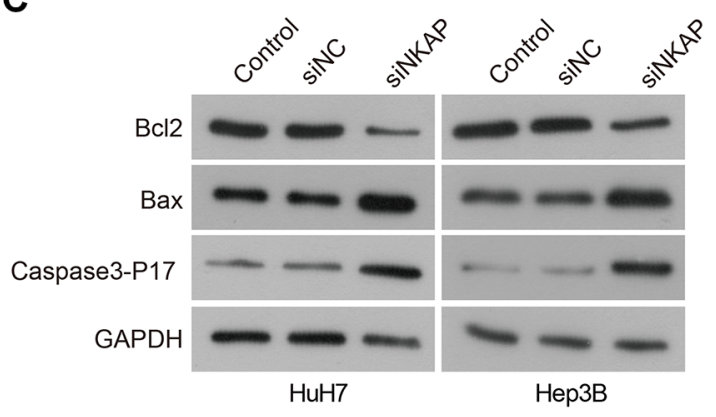

B

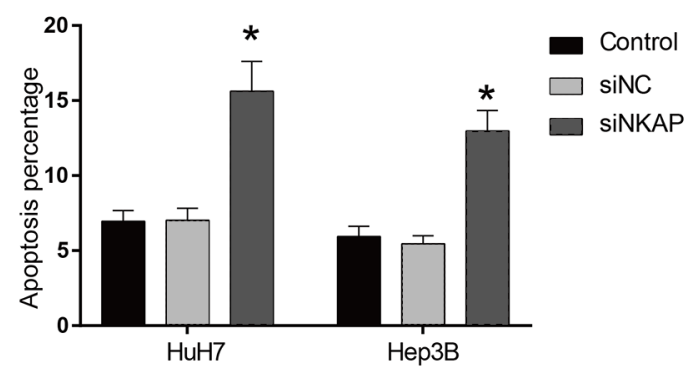

D

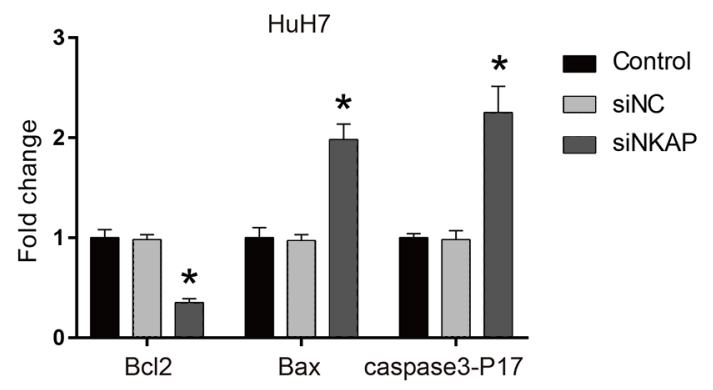

\section{E}

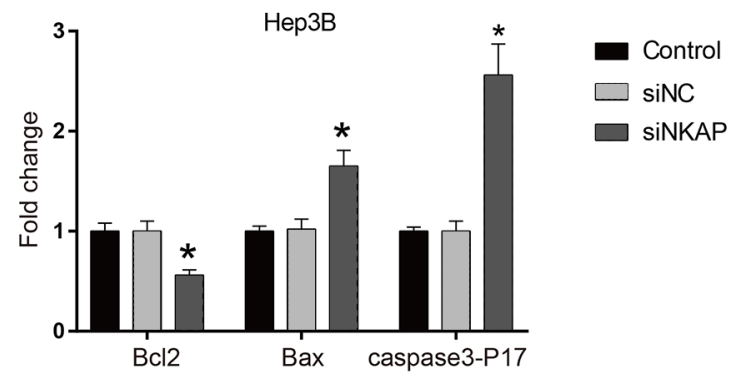

Figure 4. NKAP knockdown induced cell apoptosis by changing apoptosis related protein expression. A and B) Cell apoptosis of HuH7 and Hep3B is detected by flow cytometry; C-E) The expression of apoptosis related proteins Bcl2, Bax and Caspase3-P17 is detected by western blot. HCC, hepatocellular carcinoma. ${ }^{\star}$ represents $\mathbf{p}<\mathbf{0 . 0 5}$. 

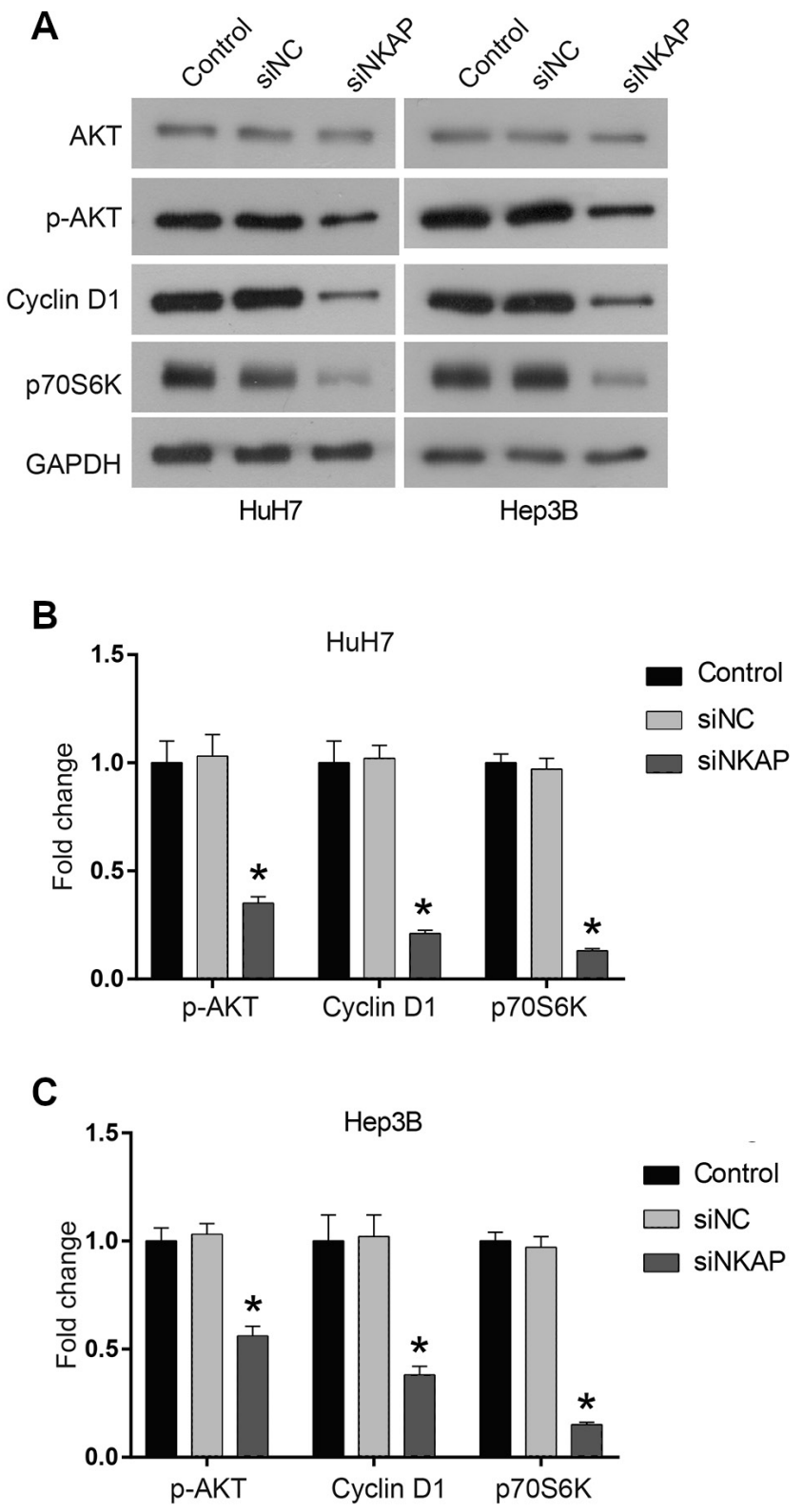

Figure 5. NKAP knockdown inhibited HCC through AKT signaling pathway. Western blot image $(A)$ and quantification analyses $(B)$ and $(C)$ indicates that NKAP knockdown reduced the phosphorylation of AKT and the expression of the downstream effector CyclinD1 and p70S6K. HCC, hepatocellular carcinoma. ${ }^{*}$ represents $\mathrm{p}<0.05$.

\section{Discussion}

It has been reported that NKAP plays an important role in fundamental cell functions such as mitosis, RNA splicing and processing $[19,20]$. So it is speculated that the dysfunction of NKAP can cause important changes in cellular and organic functions, including tumorigenesis. Indeed, NKAP gene deficiency has been observed in soft tissue sarcomas as well as several other types of human cancer [20]. However, our understanding of NKAP functions in tumor remains scarce. Here for the first time, we identify the function of NKAP in HCC cell lines HuH7 and Hep3B.

By searching on GEPIA and IHC analysis, we find that the expression of NKAP is upregulated in HCC tissues compared with the paracancerous tissues, and is associated with gender and stage of patients. In terms of prognosis, HCC patients with high NKAP expression tend to have a lower survival rate. These data suggest that NKAP may play a positive role in HCC progression. CCK8 and flow cytometry assay show that NKAP knockdown significantly inhibits cell proliferation and promotes cell apoptosis in $\mathrm{HuH7}$ and Hep3B cells. As shown in previous study, NKAP is critical for chromosome alignment in mitosis and its dysfunction will impair chromosome stability [20]. Here we demonstrate NKAP knockdown inhibits cell proliferation and induces cell apoptosis, which may be associated with chromosome instability induced by NKAP impairment. Western blot analysis shows that cell apoptosis related protein expression is also changed by NKAP knockdown, including increased Bax and Caspase3-P17 and decreased Bcl2. As is well-known, Caspase3-P17 and Bax are key apoptosis initiation proteins in mitochondrial apoptosis pathway [26, 27]. And $\mathrm{Bcl} 2$ functions as an anti-apoptotic protein by antagonizing Bax $[28,29]$. The changes of apoptosis related proteins are consistent with the pro-apoptotic effect of NKAP knockdown. In addition, we also examine the effect of NKAP knockdown on cell invasion of two HCC cell lines. Cell invasion is one of the most important factors in tumor metastasis, which is the leading cause of death in HCC patients [30]. Our data show that NKAP knockdown significantly inhibits cell invasion in HuH7 and Hep3B cells, which suggests that NKAP functions as a promoter in HCC metastasis. Moreover, the oncogenic function of NKAP was also proved in human AGS and MKN45 gastric cancer cells.

As described in previous studies, NKAP knockdown will lead to an increase in cellular pre-mRNA proportion and chromosome misalignment which further cause cell cycle arrest $[19,20]$. However, the accurate mechanism by which NKAP functions in tumor remains unclear. As is commonly known, AKT signaling pathway has been reported to regulate numerous biological processes such as cell proliferation, survival, protein synthesis, and so on $[31,32]$. Here, we found that NKAP knockdown significantly inhibited the activation of AKT signaling pathway, including decreased p-AKT level and downstream proteins, Cyclin D1 and p70S6K.

In summary, our study for the first time reveals that NKAP plays an oncogenic function through AKT signaling pathway in HCC in vitro. Our results may provide a potential target for the treatment of HCC.

Supplementary information is available in the online version of the paper. 


\section{References}

[1] CHAISAINGMONGKOL J, BUDHU A, DANG H, RABIBHADANA S, PUPACDI B et al. Common Molecular Subtypes Among Asian Hepatocellular Carcinoma and Cholangiocarcinoma. Cancer Cell 2017; 32: 57-70.e3. https://doi. org/10.1016/j.ccell.2017.05.009

[2] CANCER GENOME ATLAS RESEARCH NETWORK. Comprehensive and Integrative Genomic Characterization of Hepatocellular Carcinoma. Cell 2017; 169: 1327-1341. e23. https://doi.org/10.1016/j.cell.2017.05.046

[3] CHUANG SC, LA VECCHIA C, BOFFETTA P. Liver cancer: descriptive epidemiology and risk factors other than HBV and HCV infection. Cancer Lett 2009; 286: 9-14. https://doi.org/10.1016/j.canlet.2008.10.040

[4] ROBERTS LR. Sorafenib in liver cancer - just the beginning. N Engl J Med 2008; 359: 420-422. https://doi.org/10.1056/ NEJMe0802241

[5] LIAO Y, ZHENG Y, HE W, LI Q, SHEN J et al. Sorafenib therapy following resection prolongs disease-free survival in patients with advanced hepatocellular carcinoma at a high risk of recurrence. Oncol Lett 2017; 13: 984-992. https://doi. org/10.3892/ol.2016.5525

[6] ELZOUKI AN, ELKHIDER H, YACOUT K, AL MUZRAKCHI A, AL-THANI S et al. Metastatic hepatocellular carcinoma to parotid glands. Am J Case Rep 2014; 15: 343-347. https://doi.org/10.12659/AJCR.890661

[7] GOKCAN H, SAVAS N, OZTUNA D, MORAY G, BOYVAT F et al. Predictors of Survival in Hepatocellular Carcinoma Patients. Ann Transplant 2015; 20: 596-603. https:// doi.org/10.12659/AOT.894878

[8] YU LH, YU WL, ZHAO T, WU MC, FU XH et al. Post-operative delayed elevation of ALT correlates with early death in patients with HBV-related hepatocellular carcinoma and Post-hepatectomy Liver Failure. HPB (Oxford) 2018; 20: 321-326. https://doi.org/10.1016/j.hpb.2017.10.001

[9] CUI H, ZHANG Y, ZHANG Q, CHEN W, ZHAO H et al. A comprehensive genome-wide analysis of long noncoding RNA expression profile in hepatocellular carcinoma. Cancer Med 2017; 6: 2932-2941. https://doi.org/10.1002/cam4.1180

[10] YE B, HU B, ZHENG Z, ZHENG R, SHI Y. The long noncoding RNA AK023948 enhances tumor progression in hepatocellular carcinoma. Exp Ther Med 2017; 14: 3658-3664. https://doi.org/10.3892/etm.2017.5019

[11] CHEN D, LI Z, YANG Q, ZHANG J, ZHAI Z et al. Identification of a nuclear protein that promotes NF- $\kappa \mathrm{B}$ activation. Biochem Biophys Res Commun 2003; 310: 720-724. https:// doi.org/10.1016/j.bbrc.2003.09.074

[12] THAPA P, CHEN MW, MCWILLIAMS DC, BELMONTE $\mathrm{P}$, CONSTANS $\mathrm{M}$ et al. NKAP Regulates Invariant NKT Cell Proliferation and Differentiation into ROR-gammatExpressing NKT17 Cells. J Immunol 2016; 196: 4987-4998. https://doi.org/10.4049/jimmunol.1501653

[13] PAJEROWSKI AG, NGUYEN C, AGHAJANIAN H, SHAPIRO MJ, SHAPIRO VS. NKAP is a transcriptional repressor of notch signaling and is required for $\mathrm{T}$ cell development. Immunity 2009; 30: 696-707. https://doi.org/10.1016/j.immuni.2009.02.011
[14] THAPA P, DAS J, MCWILLIAMS D, SHAPIRO M, SUNDS$\mathrm{BAK} \mathrm{R}$ et al. The transcriptional repressor NKAP is required for the development of iNKT cells. Nat Commun 2013; 4: 1582. https://doi.org/10.1038/ncomms 2580

[15] HSU FC, PAJEROWSKI AG, NELSON-HOLTE M, SUNDSBAK R, SHAPIRO VS. NKAP is required for $\mathrm{T}$ cell maturation and acquisition of functional competency. J Exp Med 2011; 208: 1291-1304. https://doi.org/10.1084/ jem.20101874

[16] DASH B, SHAPIRO MJ, CHUNG JY, ROMERO AROCHA S, SHAPIRO VS. Treg-specific deletion of NKAP results in severe, systemic autoimmunity due to peripheral loss of Tregs. J Autoimmun 2018; 89: 139-148. https://doi. org/10.1016/j.jaut.2017.12.013

[17] WORLITZER MM, SCHWAMBORN JC. The Notch corepressor protein NKAP is highly expressed in adult mouse subventricular zone neural progenitor cells. Neuroscience 2014; 266: 138-149. https://doi.org/10.1016/j.neuroscience.2014.02.019

[18] PAJEROWSKI AG, SHAPIRO MJ, GWIN K, SUNDSBAK R, NELSON-HOLTE M et al. Adult hematopoietic stem cells require NKAP for maintenance and survival. Blood 2010; 116 : 2684-2693. https://doi.org/10.1182/blood-2010-02-268391

[19] BURGUTE BD, PECHE VS, STECKELBERG AL, GLOCKNER G, GASSEN B et al. NKAP is a novel RS-related protein that interacts with RNA and RNA binding proteins. Nucleic Acids Res 2014; 42: 3177-3193. https://doi.org/10.1093/nar/ gkt1311

[20] LI T, CHEN L, CHENG J, DAI J, HUANG Y et al. SUMOylated NKAP is essential for chromosome alignment by anchoring CENP-E to kinetochores. Nat Commun 2016; 7: 12969. https://doi.org/10.1038/ncomms12969

[21] WINTERHOFF B, HAMIDI H, WANG C, KALLI KR, FRIDLEY BL et al. Molecular classification of high grade endometrioid and clear cell ovarian cancer using TCGA gene expression signatures. Gynecol Oncol 2016; 141: 95-100. https://doi.org/10.1016/j.ygyno.2016.02.023

[22] GTEX CONSORTIUM. Human genomics. The GenotypeTissue Expression (GTEx) pilot analysis: multitissue gene regulation in humans. Science 2015; 348: 648-660. https:// doi.org/10.1126/science.1262110

[23] TOMCZAK K, CZERWINSKA P, WIZNEROWICZ M. The Cancer Genome Atlas (TCGA): an immeasurable source of knowledge. Contemp Oncol (Pozn) 2015; 19: A68-A77. https://doi.org/10.5114/wo.2014.47136

[24] TANG Z, LI C, KANG B, GAO G, LI C et al. GEPIA: a web server for cancer and normal gene expression profiling and interactive analyses. Nucleic Acids Res 2017; 45: W98W102. https://doi.org/10.1093/nar/gkx247

[25] CARNERO A, BLANCO-APARICIO C, RENNER O, LINK W, LEAL JF. The PTEN/PI3K/AKT signalling pathway in cancer, therapeutic implications. Curr Cancer Drug Targets 2008; 8: 187-198.

[26] GUI D, GUO Y, WANG F, LIU W, CHEN J et al. Astragaloside IV, a novel antioxidant, prevents glucose-induced podocyte apoptosis in vitro and in vivo. PLoS One 2012; 7: e39824. https://doi.org/10.1371/journal.pone.0039824 
[27] MARTINOU JC, YOULE RJ. Mitochondria in apoptosis: Bcl-2 family members and mitochondrial dynamics. Dev Cell 2011; 21: 92-101. https://doi.org/10.1016/j.devcel.2011.06.017

[28] YANG TQ, LU XJ, WU TF, DING DD, ZHAO ZH et al. MicroRNA-16 inhibits glioma cell growth and invasion through suppression of BCL2 and the nuclear factor-kappaB1/MMP9 signaling pathway. Cancer Sci 2014; 105: 265-271. https:// doi.org/10.1111/cas.12351

[29] RADHA G, RAGHAVAN SC. BCL2: A promising cancer therapeutic target. Biochim Biophys Acta Rev Cancer 2017; 1868: 309-314. https://doi.org/10.1016/j.bbcan.2017.06.004
[30] TANG X, ZHA L, LI H, LIAO G, HUANG Z et al. Upregulation of GNL3 expression promotes colon cancer cell proliferation, migration, invasion and epithelial-mesenchymal transition via the Wnt/ $\beta$-catenin signaling pathway. Oncol Rep 2017; 38: 2023-2032. https://doi.org/10.3892/or.2017.5923

[31] XU K, CHEN G, LI X, WU X, CHANG Z et al. MFN2 suppresses cancer progression through inhibition of mTORC2/Akt signaling. Sci Rep 2017; 7: 41718. https://doi. org/10.1038/srep41718

[32] FRANKE TF, HORNIK CP, SEGEV L, SHOSTAK GA, SUGIMOTO C. PI3K/Akt and apoptosis: size matters. Oncogene 2003; 22: 8983-8998. https://doi.org/10.1038/sj.onc.1207115 